\title{
Social Media News: A Comparative Analysis of the Journalistic Uses of Twitter
}

\author{
Rossella Rega \\ ORCID: 0000-0002-1827-7425 \\ University of Siena, Italy
}

\begin{abstract}
The article investigates media organizations' strategies to adapt to the new media ecology in which Twitter is renewing traditional news-production routines. Two main strategies are identified: a traditional approach aimed at one-way news dissemination, and a journalistic model that recasts the relationship with the audience and uses Twitter as a community-building tool. It has been assumed that media outlets' endeavors to gain centrality in the information system are associated with their ability in using the appropriate communication tools of Twitter and the implementation of strategies based on interaction with users. Based on a comparative analysis of Twitter uses by newspapers in 31 countries, the study shows that the ability to manage the structural elements of the platform is widespread among media organizations. Concurrently, the relational strategy, i.e. the investment in community building, although less widespread, is present in many countries and leads to an increased level of user involvement.
\end{abstract}

KEYWORDS: Twitter, social media, digital journalism, news organizations, participatory journalism.

\section{INTRODUCTION}

The rapid spread of social media among information professionals has modified traditional news-making production routines and practices, posing new challenges for mainstream media organizations. The latter have been forced by the shift of readers to social media sites to search for new business models and to identify editorial growth strategies allowing a more substantial use of new digital platforms. Research in this area has found that the introduction of such tools into the ordinary practices of news production may constitute a useful resource for attracting new audiences by offering a wide range of content and news. Twitter, a platform characterized by high journalistic suitability (Hermida, 2010), can be considered an important medium through which media organizations can spread and become more visible, thus reinforcing their brand. However, 
the ability of such organizations to adapt to the new digital environment has not been rapid and easy everywhere. Indeed, their engagements with this new reality immediately highlighted the difficulty of defining and managing an effective strategy for a social media presence. In many cases this led to conservative reactions, such as choosing to cling as long as possible to traditional journalistic practices and preferring to "underuse" the microblog (Boyle \& Zuegner, 2012; Herrera \& Requejo, 2012). Evidence of this "underuse" is found in the choice of many news outlets to employ Twitter as an additional space for spreading their content in accordance with the one-way and self-referential communication model, which has a poor performance in terms of audience engagement (Ju et al., 2014; Messner et al., 2012). In other words, although Twitter offers unique interactive features, which allow for a two-way model of communication, the practical exploitation of these seems so far to be limited. Indeed, the use of Twitter as a tool for increasing audience participation and loyalty is a goal which media in many countries have yet to reach.

In light of this scenario of "partial" adoption of the medium, this study aims to identify the communication strategies which media organizations around the world have developed on Twitter, and to measure their impact on audience engagement. The study conducted comparative analysis of the uses of Twitter by media organizations in 31 countries (in North America and Europe, plus Australia). The article discusses the relationship between the communication strategy developed by news organizations on Twitter and user reactions (retweets, replies and likes). The basic idea is that a model which uses the microblog as a community-building tool will gain more grassroots appreciation (from users), thus increasing the visibility of the news outlet.

The following section presents a theoretical framework of the comparative studies on journalism and the use of Twitter by media outlets, followed by an explanation of the research design and methodology. The main results will then be highlighted and discussed, and some useful indications for further analysis will be suggested in the concluding remarks.

\section{THEORETICAL FRAMEWORK}

The development of Information and Communication Technology (ICT) and the spread of social media among information professionals have transformed media organizations and redefined relations between citizens and media, raising new challenges for journalistic systems.

In this regard, studies that have updated the diffusion innovation theory in order to explain the adoption of social media by news organizations (Ekdale et al., 2015) distinguish between three interconnected waves of change: (i) technology 
use, (ii) audience relationship, and (iii) professional culture. While the first wave is relatively simple, as the need to adapt journalistic practices to new platforms and the advantages of doing so are shared convictions, the second encounters strong resistance from journalists and media organizations. Indeed, it requires a reformulation of their relationship with audiences, who become both critics and partners in content production (von Nordheim et al., 2018). The third wave, which includes a reconfiguration of the professional culture of news organizations and experimentation with new business models, is far from completion. The main challenge for news organizations is now the need to reinforce relationships with users.

New media with the technical aid of digital culture enables open participation, which requires openly diffused, rather than centrally controlled, content. However, this is an issue in which theoretical statements often depart from empirical evidence. For instance, the comparative analysis by Humprecht and Esser (2018) of 48 websites of news organizations in France, Italy, Germany, UK, USA and Switzerland shows that their investment in bottom-up participation promotion is currently very poor, despite their statements about the importance of participation. Crucially the same results are found in web-based outlets, which place a high value on participation in order to present an alternative to the mainstream media (Humprecht \& Esser, 2018). Overall, although new opportunities for interaction have sometimes led to innovative forms of collaboration between journalists and audience communities (Hermida, 2012), tension has grown between the ethics of open participation and the sense of loss of control experienced by journalists (Lewis, 2012). When trained for a traditional newsroom culture, journalists tend to struggle to adopt one of open participation (Lewis \& Westlund, 2015). This tension can also be found among social media and newsroom editors (Pak, 2019).

If we focus our attention on social media, the issue of user/reader involvement becomes central, and it is widely recognized that the online visibility of news organization content is highly dependent on audience activation (Christin, 2020). For example, news can quickly spread throughout a network "if many users (nodes) share (distribute) the item" (Welbers \& Opgenhaffen, 2018, p. 3). Indeed, news users (Larsson, 2018) are constantly engaged in the information process, and involved in "gatewatching" activities (Bruns, 2015) and the co-production and dissemination of news (Hermida, 2010). The relevance of journalistic content is therefore determined by the magnitude of the flow and the degree of intensity of online discussion produced by the news content.

Twitter and Facebook in particular, whose affordances increase their resources for engagement and facilitate audience participation (Papacharissi, 2016), played a salient role in connecting news outlets with increasingly participatory online audiences (García-Perdomo et al., 2017), thus renewing journalistic news values 
and practices. After the introduction of these platforms, the majority of news organizations created social media accounts and integrated them into their websites, "making them part of the news experience" (Al Rawi, 2017, p. 706). But the most important issue is how they use these tools. Acquiring a social media account is pointless if the benefits it offers are not fully exploited. In this regard, most studies examining news outlet social media accounts reveal the traditional pattern of the one-way distribution model (or broadcast model) (GarcíaPerdomo et al. 2017; Malik \& Pfeffer, 2016). This is a strategy that dominated the initial phase of social media adoption (Hermida, 2013) but still seems to prevail in many cases for the purpose of directing traffic to the news outlet's own website (Lasorsa et al., 2012; Malik \& Pfeffer, 2016). The predominance of the broadcast model and the lack of interactivity with audiences have also been highlighted by several studies looking at newspapers and national, regional and local television news organizations (Armstrong \& Gao, 2010), local television (Greer \& Ferguson, 2011), news agencies (Bloom et al., 2016), and global media organizations (Malik \& Pfeffer, 2016). In short, the use of social media as an additional news distribution platform in accordance with a one-way communication model seems to be prevalent. However, given the huge amount of information available on social media, simply publishing news on Twitter is insufficient to compete successfully for the limited attention of users. The type of content published can make the difference (Pak, 2019), as can the use of specific features of social media platforms that allow interaction with users and increase their interest and reactions. Users can be active participants in the diffusion process because their engagement with news content (i.e. retweets, replies and favorites) makes it visible to their networks (Welbers \& Opgenhaffen, 2018), thereby promoting its propagation throughout the web (Hermida et al., 2012).

Regarding the uses of Twitter by media organizations, the main goal of the valorization of participatory and relational aspects is not to create a proper conversation, as this is not an objective for media outlets. The aim is to use the microblog as a community tool to organize readers' involvement in the editorial process (Hermida, 2013). This is an approach that presupposes a certain degree of familiarity with Twitter and with the use of its technical features for community building. Content posted online is not merely a copy of the online edition but is an ad-hoc version, which takes the specificity of the media environment into account (Rega, 2017). Following this strategy, the factors that enable media organizations to enhance their communication activities are the specific "structural features" of Twitter (hashtag, hyperlink and mention), and more importantly, the management of the "relational features" (retweets, replies and favorites) that makes it possible to express interest about the content published by users and to interact with them. 
Skillfulness, i.e. the capacity to use the various features of the platform effectively, has become increasingly central after changes in the timeline construction algorithm ${ }^{1}$. This is now based on the relevance of sources and interactions generated by news in terms of received retweets, replies and favorites. The results of a comparative study by Engesser and Humprecht (2015), which analyzed 38 media organizations in five countries (France, Germany, Italy, UK and USA), are worth noting in this regard. They reveal a clear predominance of the quantitative approach (the quantity of published posts) over skillfulness (competence in using Twitter) and show that the two approaches are mutually exclusive. Comparative research carried out in the USA by Wang (2016) examined 20 television programs to determine the relationship between Twitter use and the level of program appreciation. Three specific metrics for comparing media outlet communication strategies were introduced, and an interaction-based strategy (involving a conversational use of Twitter based on retweets, replies, and tweets with mentions) emerged as the most effective way to increase program appreciation. This is an important confirmation of the crucial role that the interactional model plays for media outlets. Similarly, a study on the uses of Twitter by 28 Italian media organizations (Bracciale \& Martella, 2016) concluded that although the broadcast use predominates, a dialogical strategy is more effective in terms of audience engagement.

When examining recent changes in the journalistic environment, a comparative analysis of different countries makes it possible to trace those common constants that traverse diverse contexts and to identify factors underlying the differences. In this regard, the text by Hallin and Mancini 'Comparing Media Systems' (2004), is an indispensable reference. The authors provided the basis for comparative research by analyzing interconnections between political systems in North America and Western Europe. Almost 17 years after its publication, many scholars have tried to readapt the models of journalism (Liberal, Democratic Corporatist and Polarized Pluralist) to transformations of contemporary societies and the need to review and update the analysis dimensions of media systems has been widely stressed (Brüggemann et al., 2014; Mattoni \& Ceccobelli, 2018; Hallin \& Mancini, 2017; Norris, 2009). Indeed, the study needs to be expanded beyond the original 18 countries, and indicators and analysis dimensions need to be updated to consider the transformations of the media ecosystem ${ }^{2}$. The theoretical framework of the study by Hallin and Mancini (2004) was based on a pre-digital context, whereas today's norms, actors and digital media logics

1 Twitter does not furnish details on its algorithms of timeline construction, but since February 2016 the visualization of tweet flows has been modified. It is based by default not on chronological order but on interaction factors.

2 The dimensions of analysis originally considered were political parallelism, media markets, journalistic professionalism and state intervention (Hallin \& Mancini, 2004). 
are intertwined giving a prominent role to non-institutional actors. In order to build on Hallin and Mancini's (2004) work and update their framework, this study was carried out on how media outlets are using Twitter to renew their news production practices and regain centrality in the information system.

\section{HYPOTHESES AND RESEARCH QUESTIONS}

Twitter uses by media organizations have been linked to two main communication strategies: (i) a more traditional approach, aimed at one-way dissemination of news (Hermida, 2013), and (ii) a two-way communication approach, to reinforce participation and the sense of community among audiences (Meyer \& Tang, 2015). Most studies agree that media organizations tend not to exploit social media to their full potential (Herrera \& Requejo, 2012; Meyer \& Tang, 2015) but limit themselves to using a broadcast communication model (Malik \& Pfeffer, 2016). This scenario is comparable to the first stages of website use by news organizations, when paper format content was repeated online as "shovelware" (Singer, 2001). Regarding audience engagement, e.g., sharing behavior (retweets) or users' ratings (favorites/likes), adopting this model of Twitter use has proved ineffective because it is unable to stimulate either interest or reaction from users (Boyle \& Zuegner, 2012; Greer \& Ferguson, 2011; Ju et al., 2014). In other words, the regular publication of news content using a one-way approach is not enough to strengthen the visibility of the news organization in information flows. Efforts to boost listening activities and interaction with users are also needed in order to stimulate sharing and liking behavior. The valorization of participatory and relational features of the platform through the adoption of audience interaction-based strategies represents a key factor for media organizations. First, it fosters user ranking and sharing behavior, thus improving news media visibility (Wang, 2016), and secondly it increases loyalty to and trust in the brand, resulting in an increase in the number of readers (Welbers \& Opgenhaffen, 2018).

For these reasons it has been assumed that when an interaction-based approach to Twitter use is predominant - characterized by an effective use of the relational features (retweets, replies and favorites) which encourages user interest and involvement - better results are achieved in terms of content engagement (retweets and favorites received). The news outlets with the highest levels of audience engagement are those that make targeted efforts in community-building practices (Meyer \& Tang, 2015) and pay particular attention to content production and its publishing platform.

These latter considerations open the way for the following hypothesis: 
- The interaction-based strategy of media outlets - characterized by dialogue and interaction with users (news outlet retweets, replies, and favorites ${ }^{3}$ ) has a greater capacity for audience engagement (user retweets, replies, and favorites received) than the broadcast communication model (frequency-based strategy).

Based on this hypothesis, the study sets out to answer the following research questions:

- (RQ1) What communication strategies have been implemented by media organizations to manage their presence on Twitter?

- (RQ2) What effects do these strategies have on audiences in terms of engagement?

\section{RESEARCH STRATEGY, DATA, AND DESIGN}

The study examines media organizations' Twitter accounts, identified on their websites, from 31 different countries (in Europe ${ }^{4}$ and North America, plus Australia). The five media organizations with the highest circulation were selected from each country, based on a list from the World Association of Media Organizations and News Publishers (WAN-IFRA, 2017). The rationale for this choice was the assumption that these organizations would have the most modern outlook and be the most skilled and invested in ICT. In some countries, fewer than five media organizations were examined because none of the others had a Twitter account.

The study was conducted on both profiles and timelines ${ }^{5}$ of 133 active accounts, namely those that published at least one post during the analysis period of 2 July 2017 to 2 August 2017 (Appendix 1). A total of 232,012 posts - tweets, retweets and replies - produced by the accounts were downloaded.

On the basis of previous findings (Bracciale \& Martella, 2016; Engesser \& Humprecht, 2015; Wang, 2016), media organizations' communication strategies on Twitter were operationalized through specific indicators regarding their activity on the platform. Each indicator (number of tweets, retweets etc.)

3 The news outlet practices of retweeting, replying to and liking users' posts.

4 Cyprus and Malta were excluded from the analysis because of their absence from the database (WAN-IFRA, 2017). In comparison with Hallin and Mancini's study (2004), other European countries and Australia were included in the analysis.

5 The download of media outlets' timelines was conducted by the author using the Twitter REST API (https://dev.twitter.com/rest/public). Author would like to thank Roberta Bracciale for her assistance with data processing. 
was normalized to create different indexes ${ }^{6}$ able to identify variations on the strategies related to the use of the platform (Table 1). Because the variation of media organizations' tweeting strategies was skewed, a relative index based on the sample mean was created. This choice made it possible to quantify the patterns of each media organization by comparing it with the mean score of the organizations in each dimension.

Table 1. Indexes of newspapers' communicative strategies

\begin{tabular}{|c|c|c|}
\hline n. & Index & Operational definition \\
\hline 1. & Tweet Index & Number of published tweets in relation to the sample average. \\
\hline 2. & Hashtag Index & Number of tweets with a \#hashtag in relation to the sample average. \\
\hline 3. & Mention Index & Number of tweets with a @mention in relation to the sample average. \\
\hline 4 & Reply Index & Number of the account's replies in relation to the sample average. \\
\hline 5. & Retweet Index & Number of the account's retweets in relation to the sample average. \\
\hline 6. & Favorite Index & Number of the account's favorites in relation to the sample average. \\
\hline
\end{tabular}

In order to identify the communication strategies of the media organizations, the indexes of media organizations' tweeting habits were synthesized through a principal components analysis ${ }^{7}$ (PCA) to reduce the number of variables. Factors extracted with the PCA were then set in relation to engagement indexes of Twitter users to verify which strategy implemented by media organizations was the most suitable for activating audiences. This was detected by using a Log-linear multiple regression model.

To enable the analysis to be carried out, engagement indicators of users' behavior were also normalized to create specific indexes that would consider variations in the effects produced by the adopted communication strategies. These engagement indexes were used as dependent variables (Table 2).

6 Considering the power law distribution (skewed) characteristic of scale-invariant networks, it was considered preferable to normalize data using average ratios built on the registered average for each indicator in the sample. This procedure makes it possible to compare the media organizations' strategies, highlighting their habits in the uses of Twitter.

7 PCA is a multivariate analysis technique used to summarize several analyzed cardinal variables in new dimensions, i.e. the principal components. The latter are mutually orthogonal, i.e. statistically independent, and express a linear combination of the starting variables. They reproduce the characteristics of the data set based on decreasing importance factors. 
Table 2. Indexes of engagement of Twitter users

\begin{tabular}{|c|c|c|}
\hline n. & Index & Operational definition \\
\hline 1. & Sharing Index & Number of received retweets in relation to the sample average. \\
\hline 2. & Ranking Index & Number of received favorites in relation to the sample average. \\
\hline
\end{tabular}

\section{FINDINGS AND DISCUSSION}

The application of the PCA shows that the first two ${ }^{8}$ factors are significant and can explain $52.1 \%$ of the total variance of differences among media organizations (Table 3). The first factor (31.8\%) indicates the existence of a strategy strongly anchored to the relational dimension. This first component is, in fact, characterized by the presence of replies to other accounts (0.8), and retweets and favorites (0.7) produced by other users. These elements suggest a communication strategy that carefully monitors the conversational flow of the platform and actively intervenes in it. This first factor identifies the appropriation of Twitter and its potential for community building and can be called the "interaction" factor.

The second factor (20.3\%) identifies the adoption of a more traditional communication model based on frequency of publication and use of platform features (\#; @) which allow accounts to enter the communication flow or to attract users' attention. The saturation produced by the tweeting and by the hashtagging index (0.8) is predominant in this component. However, the relational dimension of Twitter is still poorly used. Given these considerations, the second factor can be called the "exposure" of the media organization.

Regarding the first research question, the data show the presence of two main communication strategies among the media organizations analysed. On the one hand, there is a focus on public engagement through active participation in the life of the platform (interaction). In this case, Twitter is used to build relations with users aimed at listening and dialoguing (two-way communication). On the other, there is a strategy oriented to using the platform by maintaining a presence through the constant production of posts, including useful mentions and hashtags that enhance the media organizations' visibility (one-way communication).

8 The selection of the components for the analysis was based on the combination of various criteria: the Kaiser criteria (eigenvalue $>1$ ); scree-test and cost-benefit analysis. 
Table 3. Matrix of components of media organizations' communicative strategies

\begin{tabular}{c|c|c}
\hline & \multicolumn{2}{c}{ Components } \\
\cline { 2 - 3 } & \multicolumn{2}{c}{$\mathbf{1}$ (Interaction) } \\
\hline Tweet Index & .250 & .755 \\
\hline Hashtag Index & -.092 & .762 \\
\hline Mention Index & .084 & .546 \\
\hline Reply Index & .777 & .121 \\
\hline Retweet Index & .681 & .174 \\
\hline Favourite Index & .697 & -.055
\end{tabular}

Source: Author.. Rotation method: Varimax with Kaiser normalization

The intersection of factors yields a typification of communication strategies based on the combination of factorial scores of the interaction and exposure components. Four different ideal types emerge: quadrant I, "networked"; quadrant II, "self-promoter"; quadrant III, "listless"; and quadrant IV, "connective" (Figure 1).

The positioning of the analyzed media organizations along the two factorial axes - based on their recorded average scores for the two factors of exposure (ordinate) and interaction (abscissa) - yields further insights.

The "networked" group (high exposure and high interaction) consists of those media organizations in which professionalization in the use of Twitter is mature and consolidated. This is the situation in many media outlets in Spain (El Mundo, MARCA, El Paìs, AS), France (Le Figaro, Le Monde), Ireland (The Irish Times), United States (USA Today), United Kingdom (The Daily Mirror and the Sun) and the Netherlands (Volkskrant), followed by other media organizations in the first quadrant ${ }^{9}$ (including Corriere della Sera, La Stampa and La Repubblica). High scores for both factors show that investment in community building (interaction) proceeds in conjunction with the capacity to manage elements related to the technical features of the microblog (exposure). Indeed, efforts to interact with users require overall skillfulness in recourse to Twitter by media outlets, which is reflected in the appropriate use of structural and relational elements. Regarding the three stages of the adoption of digital technologies mentioned above (Ekdale et al., 2015), in this case it seems that two waves of change were fulfilled: the first, which is related to technical appropriation, and the second, which concerns the redefinition of the relationship with audiences, considering them as partners to be engaged in the journalistic processes (von Nordheim et al., 2018). Moreover, the good performance of these media organizations seems to be in line with the levels of use of Twitter for news found in these countries,

9 In order to make Figure 1 clearer, these and other labels (of news outlets) have been hidden. 
and particularly in Spain, France, USA, UK and Ireland (Newman et al., 2017). At the same time, the decision to invest in social media as a journalistic tool may be taken by media organizations from countries whose professional cultures and journalistic traditions differ widely (e.g., Spanish polarized pluralism and American liberalism - see: Hallin \& Mancini, 2004).

The "self-promoter" group (high exposure and low interaction) comprises those media organizations in which a one-way communication model prevails, along with a well-defined investment in exposure (frequency of publication and use of hashtags and mentions). In this case, the media organizations that stand out are the Canadian The Globe and Mail, the Portuguese O Jogo Online, and some media outlets in Greece (To Vima, TA NEA), Poland (Rzeczpospolita), UK (Daily Star) and Hungary (Nemzeti Sport). Even if in these cases the use of a strategy that takes advantage of the relational potential of the platform is not evident, the frequency of post publication and the habit of using suitable Twitter communication tools suggest a strategy that invests in the promotion and visibility of one's own information content. In this group, the appropriation of Twitter by news organizations seems to be only partially complete: the technological adoption of this instrument (first wave) must be followed by a change in the relationship with social media users (second wave), which develops the capacity to involve and retain them through community building initiatives.

The "listless" group (low exposure and low interaction) comprises several media outlets from countries such as Luxembourg (Luxemburger Wort, Luxemburger Wort FR, Le Quotidien), Austria (OÖNachrichten), Hungary (kisalfold.hu), Czech Republic (Blesk Zprávy, Deník.cz, Lidové noviny, MF DNES), Bulgaria (24chasa.bg), Finland (Aamulehti, Turun Sanomat), Slovenia (Primorske novice, Svet24), and Estonia (Eesti Päevaleht, Pärnu Postimees). In these countries the journalistic appropriation of Twitter, and even the use of basic communication elements, seem to be provisional. Not only is the communication model prevalently one-way, there also seems to be a lack of publication activity and management of platform features. In other words, the adoption of Twitter seems still to be relatively unstructured, which is reflected by the fact that media organizations use their accounts mainly in an extemporaneous and casual manner. This group contains many organizations from Eastern European countries (Czech Republic, Bulgaria, Estonia and Slovenia), in which major political instability has had a negative impact on society, compromising the development of independent media and the stabilization of values and adequate professional cultures (Mancini, 2015).

Lastly, the "connective" group (low exposure and high interaction) is characterized by high investment in interaction and construction of a dialogical relation with readers, and low use of a self-promotion strategy. In this case, empirical evidence is scant because the relational approach to Twitter is rarely 
disassociated from recourse to elements related to its features. In this quadrant are several Swiss media outlets (Neue Zürcher Zeitung, Südostschweiz and TagesAnzeiger), and other media organizations such as Casnik Delo (Slovenia), Gazeta Wyborcza.pl (Poland), LA.lv (Latvia) and L'EQUIPE (France). The presence of the New York Times in this group (see Appendix 1) can be explained by its offline levels of authoritativeness, which ensure that its content is highly visible regardless of the absence of the structural elements that enhance the communication strategy (for example, it used only one hashtag during the analysis period). This finding is consistent with the results of the study by Engesser and Humprecht (2015), which shows that even though the New York Times maintains consistent publication activity on the platform, it does not resort to the inclusion, in tweets, of elements concerning the discursive structure of social media that are useful for strengthening the visibility of information content.

Figure 1. Media organizations' strategies on Twitter (projection of the most representative for each dimension by factors).

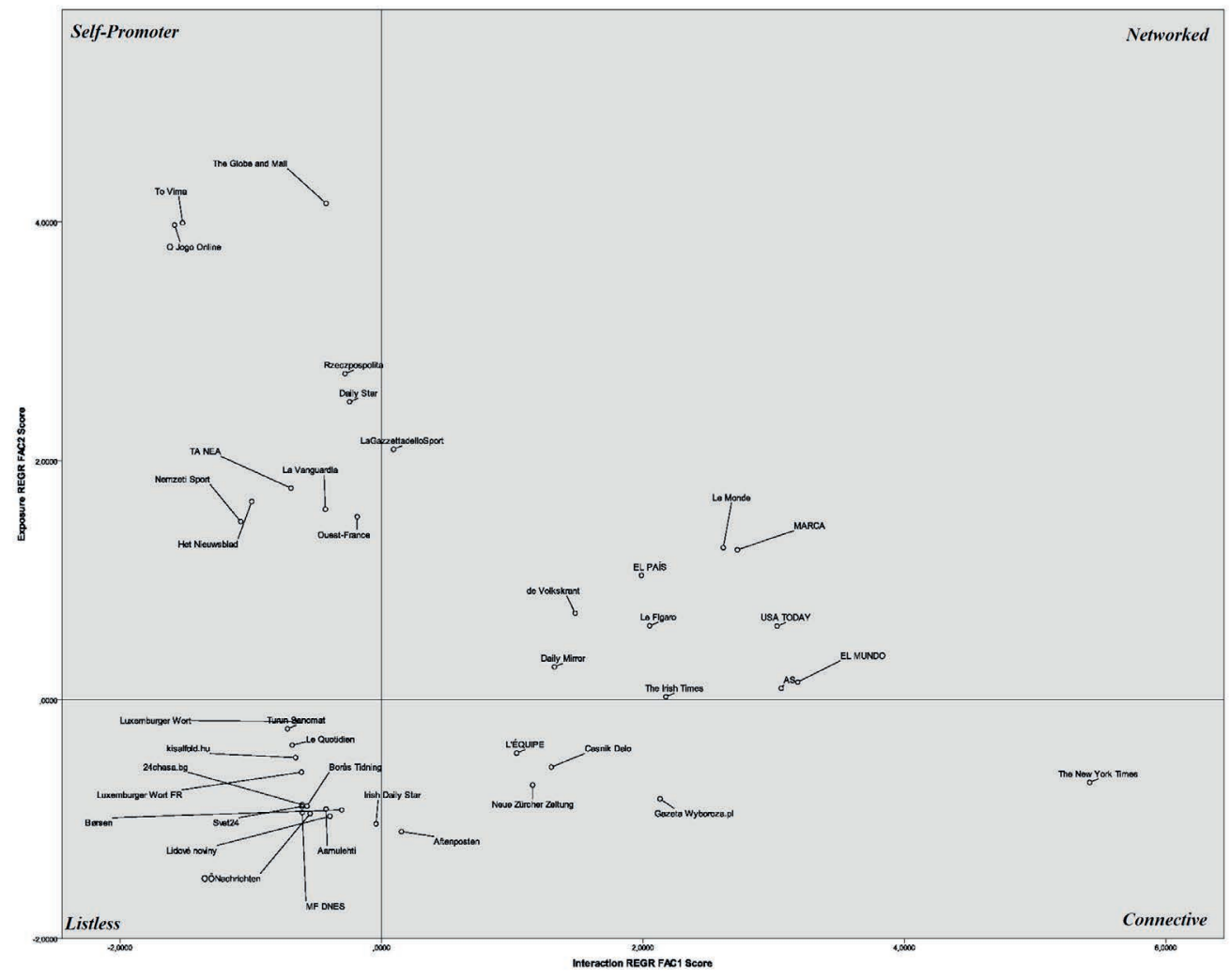

Source: Author 
The aim of the second research question was to understand the effects and impact of the communication strategies of news outlets on user activation. A log-linear logistic regression ${ }^{10}$ model was used to verify the effects of these strategies on the number of retweets and favorites received by the news outlets (Table 4).

The model applied to retweets explained $63 \%$ of the communication strategy variance of media organizations, and it showed that the adoption of an approach based on interaction results in a fivefold (390\%) increase in the probability of receiving a retweet, whereas with the use of an exposure-based approach this probability is 3.5 times (250\%) greater. A confirmation of the second hypothesis of this study is found in the fact that a strategy aimed at creating a dialogical relationship with users is more likely to involve them and to foster engagement behavior useful for increasing media organizations' visibility.

Similar results emerge from the regression carried out on the favorites, which explains $61 \%$ of the variance. The probability of receiving favorites is nearly five times greater in the case of interaction and nearly four times greater for exposure. However, in the latter case, it should be considered that the probability of receiving favorites could be explained by the presence of mentions on posts, as mentioned users may express their participation by liking the post.

Table 4. Factors predicting received retweet and favorite index

\begin{tabular}{cc|ccc}
\hline & \multicolumn{2}{c}{ Retweet Index } & \multicolumn{2}{c}{ Favourite Index } \\
\hline Predictor & Estimate $\beta$ & $\mathrm{e}^{\beta}$ & Estimate $\beta$ & $\mathrm{e}^{\beta}$ \\
\hline Intercept & $-2.951^{* * *}$ & 0.052 & $-2.9387^{* * *}$ & 0.052 \\
\hline Interaction Factor 1 & $1.592^{* * *}$ & 4.914 & $1.6070^{* * *}$ & 4.987 \\
\hline Exposure Factor 2 & $1.270^{* * *}$ & 3.563 & $1.3568^{* * *}$ & 3.883 \\
\hline Adjusted $\mathrm{R}^{2}$ & 0.632 & & 0.610 & \\
\hline $\mathrm{P}$ & $<0$ & & $<0$ & \\
$\mathrm{~N}$ & 127 & & 133 &
\end{tabular}

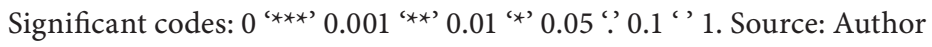

10 The multiple regression model was built using favorites and retweets as dependent variables, while the independent variables were the two PCA factors. Retweet variables were logarithmically transformed because distribution was skewed and there were several outliers because of the intrinsic characteristics of the scale invariant networks. The final log-linear regression model was: $(\log (\mathrm{Yi})=\alpha+\beta \mathrm{Xi}+\varepsilon \mathrm{i})$. To understand the effects, each predictor was transformed based on the formula $e \beta$. 


\section{CONCLUSIONS}

This study has demonstrated that, about fifteen years after the emergence of Twitter, appropriation levels of the platform by media organizations varies from one country to another. Furthermore, it emphasizes some important differences compared to the past, related to the two main communication strategies in use. On the one hand, there is a media organization's capacity to manage the appropriate communication features and structural elements of the platform. This is related to its technical structure and distinctive affordances, which are aimed at increasing the visibility of posted content. On the other hand, there is the media organization's effort to manage the dialogical elements of Twitter, with the intention of strengthening the participation and 'sense of community' of its audiences. The first approach can be considered characteristic of the first phase of technological appropriation of the microblog. The large number of media organizations in the self-promoter group suggests a partial conclusion of this phase and a normalization process of the presence of the platform in everyday editorial activities. By contrast, the challenge today seems to be concentrated on the second approach, which aims to increase interaction with users.

This renewed focus opens the way to the second wave of changes, characterized by a use of Twitter which emphasizes the involvement of readers in journalistic processes (von Nordheim et al., 2018). A news organization, from this perspective, would become a sort of informative flow hub, interacting with users as an online conversation mediator, and fostering loyalty within the community (Holton et al., 2016).

Investment by media organizations in building an interactive process with audiences seems to be the rule in many Western European countries - such as Spain, UK, France and Ireland - and the USA. An exceptional position is represented by media organizations in the United States and Spain, particularly those that have been on Twitter longer (The New York Times, AS, El Mundo, Usa Today and Marca). These cases represent contexts in which traditional print journalism has been superseded, and in which social media have reinforced their role as important tools to drive on-site traffic, off-site reach and digital subscriptions (Cornia et al., 2018). From this perspective, Twitter is an optimal tool for news organizations that use it not only for organizing reader participation in editorial processes, but also "as a way to promote consumer loyalty, which can be monetized" (Revers, 2014, p. 17). Amid the crisis of the editorial market, professional and economic interests, namely public involvement and consumer loyalty, are mutually reinforced (Krebs \& Lischka, 2019). Studies on this subject have clearly shown that the transition from "journalism as a product" to "journalism as a process", based on the valorization of bottom-up contributions, has 
a positive effect on both media organizations' centrality in information flows and business models (Moore \& Hatcher, 2018).

However, this shift of perspective is, in many cases, far from complete. This is especially true in the case of media organizations in Eastern European countries, characterized by volatile political systems which negatively influence the media context. This prevents the establishment of consolidated professional practices (Mancini, 2015). In this framework, numerous media outlets, despite having opened a Twitter account, have not adopted a communication strategy that uses the platform to its full potential.

Overall, the analysis enables the study to highlight some novel features, such as the new awareness among information professionals of the importance of using the microblog, and of taking advantage of its social media potential to reinforce public engagement. Furthermore, the effects of this strategy on readers leave no room for uncertainties and confirm, in line with previous studies (Wang, 2016), that an approach oriented to listening and interacting with users significantly increases audience engagement. The logistic regressions demonstrate the success of the strategy aimed at interacting with audiences and activating participatory behavior in followers (e.g., increase of users' sharing and ranking of content posted by the media outlet). This increases the capacity of the media organization to gain centrality in online discussion networks. Thus, investment in interaction and community building is an essential component of media outlets' presence on Twitter.

Moreover, these results, in line with previous comparative studies, show that globalization and commercial and digital trends lead to hybridization among media systems (Mellado et al., 2017). This may explain why countries characterized by different journalistic traditions and professional cultures shared similar uses of Twitter (e.g., Spain, France, UK, USA and Ireland in the "networked" group).

Finally, while it is true that it is difficult to compare media organizations with so many differences, it must be underlined that this study is only a first step. Further investigation should be oriented on broadening the analysis to other contexts, and introducing other elements, such as the extent of media market development, the degree of state intervention and the level of journalistic professionalism, in order to identify their roles in determining different adoption modalities of the microblog.

\section{REFERENCES}

Al-Rawi, A. (2017). News Organizations 2.0. Journalism Practice, 11(6), 705-720. https://doi.org/10.10 80/17512786.2016.1195239 
Armstrong, C. L., \& Gao, F. (2010). Now Tweet This: How News Organizations Use Twitter. Electronic News, 4(4), 218-235. https://doi.org/10.1177/1931243110389457

Bracciale, R., \& Martella, A. (2016). Le «tweeting habit» dei media outlet italiani. Problemi dell' informazione, 3(2016), 505-539. https://doi.org/10.1445/84857

Bloom, T., Cleary, J., \& North, M. (2016). Traversing the «Twittersphere». Journalism Practice, 10(3), 343-357. https://doi.org/10.1080/17512786.2015.1017408

Boyle, K., \& Zuegner, C. (2012). News Staffs Use Twitter to Interact with Readers. Newspaper Research Journal, 33(4), 6-19. https://doi.org/10.1177/073953291203300402

Brüggemann, M., Engesser, S., Büchel, F., Humprecht, E., \& Castro, L. (2017). Hallin and Mancini Revisited: Four Empirical Types of Western Media Systems. Journal of Communication, 64(6), 1037-1065. https://doi.org/10.1111/jcom.12127

Bruns, A. (2015). Gatekeeping, Gatewatching, Real-time Feedback: new challenges for Journalism. Brazilian Journalism Research, 10(2), 224-237. https://doi.org/10.25200/BJR.v10n2.2014.778

Christin, A. (2020). Metrics at Work: Journalism and the Contested Meaning of Algorithms. Princeton University Press.

Cornia, A., Sehl, A., Levy, D., \& Nielsen, R. K. (2018). Private Sector News, Social Media Distribution, and Algorithm Change. Reuters Institute for the Study of Journalism. https://reutersinstitute.politics. ox.ac.uk/sites/default/files/2018-10/Cornia_Private_Sector_News_FINAL.pdf

Ekdale, B., Singer, J. B., Tully, M., \& Harmsen, S. (2015). Making Change: Diffusion of Technological, Relational, and Cultural Innovation in the Newsroom. Journalism \& Mass Communication Quarterly, 92(4), 938-958. https://doi.org/10.1177/1077699015596337

Engesser, S., \& Humprecht, E. (2015). Frequency or Skilfulness. How Professional News Media Use Twitter in Five Western Countries. Journalism Studies, 16(4), 513-529. https://doi.org/10.1080/146 1670X.2014.939849

García-Perdomo, V., Salaverría, R., Kilgo, D. K., \& Harlow, S. (2017). To Share or Not to Share. Journalism Studies, 19(8), 1180-1201. https://doi.org/10.1080/1461670X.2016.1265896

Greer, C. F., \& Ferguson, D. A. (2011). Using Twitter for Promotion and Branding: A Content Analysis of Local Television Twitter Sites. Journal of Broadcasting \& Electronic Media, 55(2), 198-214. https:// doi.org/10.1080/08838151.2011.570824

Hallin, D. C., \& Mancini, P. (2004). Comparing media systems. Cambridge University Press.

Hallin, D. C., \& Mancini, P. (2017). Ten Years After Comparing Media Systems: What Have We Learned?. Political Communication, 34(2), 155-171. https://doi.org/10.1080/10584609.2016.1233158

Hermida, A. (2010). Twittering the News. Journalism Practice, 4(3), 297-308. https://doi. org $/ 10.1080 / 17512781003640703$

Hermida, A. (2012). Tweets and Truth. Journalism Practice, 6(5-6), 659-668. https://doi.org/10.1080 $/ 17512786.2012 .667269$

Hermida, A. (2013). \#JOURNALISM. Digital Journalism, 1(3), 295-313. https://doi.org/10.1080/2167 0811.2013 .808456

Hermida, A., Fletcher, F., Korell, D., \& Logan, D. (2012). Share, like, recommend. Journalism studies, 13(5-6), 815-824. https://doi.org/10.1080/1461670X.2012.664430 
Herrera, S., \& Requejo, J. L. (2012). 10 Good Practices for News Organizations Using Twitter. Journal of Applied Journalism and Media Studies, 1(1), 79-95. https://doi.org/10.1386/ajms.1.1.79_1

Holton, A. E., Lewis, S. C., \& Coddington, M. (2016). Interacting with Audiences. Journalism Studies, 17(7), 849-859. https://doi.org/10.1080/1461670X.2016.1165139

Humprecht, E., \& Esser, F. (2018). Mapping digital journalism: Comparing 48 news websites from six countries. Journalism, 19(4), 500-518. https://doi.org/10.1177/1464884916667872

Ju, A., Jeong, S. H., \& Chyi, H. I. (2014). Will Social Media Save Media organizations?. Journalism Practice, 8(1), 1-17. https://doi.org/10.1080/17512786.2013.794022

Krebs, I., \& Lischka, J. A. (2019). Is audience engagement worth the buzz? The value of audience engagement, comment reading, and content for online news brands. Journalism, 20(6), 714-732. https://doi.org/10.1177/1464884916689277

Larsson, A. O. (2018). The news user on social media: A comparative study of interacting with media organizations on Facebook and Instagram. Journalism Studies, 19(15), 2225-2242. https://doi.org/ 10.1080/1461670X.2017.1332957

Lasorsa, D. L., Lewis, S. C., \& Holton, A. E. (2012). Normalizing Twitter. Journalism Studies, 13(1), 19-36. https://doi.org/10.1080/1461670X.2011.571825

Lewis, S. C. (2012). The Tension Between Professional Control and Open Participation. Information, Communication \& Society, 15(6), 836-866. https://doi.org/10.1080/1369118X.2012.674150

Lewis, S. C., \& Westlund, O. (2015). Actors, Actants, Audiences, and Activities in Cross-Media News Work: A Matrix and a Research Agenda. Digital Journalism, 3(1), 19-37. https://doi.org/10.1080/2 1670811.2014.927986

Malik, M. M., \& Pfeffer, J. (2016). A Macroscopic Analysis of News Content in Twitter. Digital Journalism, 4(8), 955-979. https://doi.org/10.1080/21670811.2015.1133249

Mancini, P. (2015). The news media between volatility and hybridization. In J., Zielonka (Ed.), Media and politics in new democracies: Europe in a comparative perspective (pp. 28-34). Oxford University Press.

Mattoni, A., \& Ceccobelli, D. (2018). Comparing hybrid media systems in the digital age: A theoretical framework for analysis. European Journal of Communication, 33(5), 540-557. https://doi. org/10.1177/0267323118784831

Mellado, C., Hellmueller, L., Márquez-Ramírez, M., Humanes, M. L., Sparks, C., Stepinska, A., Pasti, S., Schielicke, A. M., Tandoc, E. J., Wang, H. (2017). The Hybridization of Journalistic Cultures: A Comparative Study of Journalistic Role Performance. Journal of Communication, 67(6), 944-967. https://doi.org/10.1111/jcom.12339

Messner, M., Linke, M., \& Eford, A. (2012). Shoveling tweets: An analysis of the microblogging engagement of traditional news organizations. The official research journal of the International Symposium on Online Journalism, 2(804), 74-87. https://isoj.org/wp-content/uploads/2016/10/ISOJ_Journal_ V2_N1_2012_Spring.pdf\#page $=74$

Meyer, K. M., \& Tang, T. (2015). \#SocialJournalism: Local News Media on Twitter. International Journal on Media Management, 17(4), 241-257. https://doi.org/10.1080/14241277.2015.1107569

Moore, J. E., \& Hatcher, J. A. (2018). Disrupting Traditional News Routines Through Community Engagement: Analysis of the one river, many stories media collaboration project. Journalism Studies, 20(5), 749-764. https://doi.org/10.1080/1461670X.2017.1423238 
Newman, N., Fletcher, R., Kalogeropoulos, A., Levy, D., \& Nielsen, R. K. (2017). Digital News Report 2017. Reuters Institute for the Study of Journalism. https://reutersinstitute.politics.ox.ac.uk/sites/ default/files/Digital\%20News\%20Report\%202017\%20web_0.pdf.

Norris, P (2009). Comparative Political Communications: Common Frameworks or Babelian Confusion?. Government and Opposition, 44(03), 321-340. https://doi.org/10.1111/j.1477-7053.2009.01290.x Pak, C. (2019). News Organizations' Selective Link Sharing as Gatekeeping : A Structural Topic Model Approach. Computational Communication Research, 1(1), 45-78. https://doi.org/10.31235/osf.io/pt7es

Papacharissi, Z. (2016). Affective publics and structures of storytelling: sentiment, events and mediality. Information, Communication \& Society, 19(3), 307-324. https://doi.org/10.1080/1369118X.2015.1109697 Rega, R. (2017). Le testate su Twitter e la scommessa delle soft news. Comunicazione Politica, 3(2017), 459-480. https://doi.org/10.3270/87973

Revers, M. (2014). The Twitterization of News Making: Transparency and Journalistic Professionalism. Journal of Communication, 64(5), 806-826. https://doi.org/10.1111/jcom.12111

Singer, J. B. (2001). The Metro Wide Web: Changes in newspapers' gatekeeping role online. Journalism \& Mass Communication Quarterly, 78(1), 65-80. https://doi.org/10.1177/107769900107800105 von Nordheim, G., Boczek, K., \& Koppers, L. (2018). Sourcing the Sources. Digital Journalism, 6(7), 807-828. https://doi.org/10.1080/21670811.2018.1490658

Wang, Y. (2016). How do television networks use twitter? Exploring the relationship between Twitter use and television ratings. Southern Communication Journal, 81(3), 125-135. https://doi.org/10.10 80/1041794X.2015.1116593

Welbers, K., \& Opgenhaffen, M. (2019). Presenting News on Social Media. Digital Journalism 7(1), 45-62. https://doi.org/10.1080/21670811.2018.1493939

\section{APPENDIX 1 - AVERAGE INTERACTION AND EXPOSURE FACTORS BY MEDIA ORGANIZATIONS ON TWITTER}

\begin{tabular}{|c|c|c|c|c|c|c|}
\hline Media outlet & Nation & Online & Followers & Followings & $\begin{array}{r}\text { Interaction } \\
\text { FAC1 }\end{array}$ & $\begin{array}{r}\text { Exposure } \\
\text { FAC2 }\end{array}$ \\
\hline Sydney Morning Herald & Australia & 2008 & 690149 & 722 & -0.23479 & 0.31456 \\
\hline The Daily Telegraph & Australia & 2007 & 169575 & 14305 & 0.04317 & 0.2137 \\
\hline Herald Sun & Australia & 2009 & 291078 & 34820 & 0.98748 & -0.35305 \\
\hline KURIER & Austria & 2009 & 80973 & 2012 & 0.02614 & 0.29596 \\
\hline Kleine Zeitung & Austria & 2008 & 34663 & 642 & -0.53166 & -0.59366 \\
\hline Tiroler Tageszeitung & Austria & 2009 & 4649 & 17 & -0.57698 & -0.60577 \\
\hline Kronen Zeitung & Austria & 2011 & 26346 & 36 & -0.31231 & -0.70671 \\
\hline OÖNachrichten & Austria & 2009 & 3031 & 211 & -0.54589 & -0.95544 \\
\hline Het Nieuwsblad & Belgium & 2007 & 76599 & 1227 & -0.99279 & 1.65864 \\
\hline Sudpresse & Belgium & 2009 & 56975 & 1662 & -0.33998 & -0.18772 \\
\hline De Standaard & Belgium & 2009 & 289129 & 626 & -0.50923 & -0.19745 \\
\hline HBvL & Belgium & 2008 & 35140 & 18 & -0.58395 & -0.75164 \\
\hline
\end{tabular}




\begin{tabular}{|c|c|c|c|c|c|c|}
\hline Media outlet & Nation & Online & Followers & Followings & $\begin{array}{r}\text { Interaction } \\
\text { FAC1 }\end{array}$ & $\begin{array}{r}\text { Exposure } \\
\text { FAC2 }\end{array}$ \\
\hline Dnevnik (The Daily) & Bulgaria & 2009 & 126346 & 498 & -0.55442 & -0.66753 \\
\hline Trud.bg & Bulgaria & 2009 & 8771 & 99 & -0.58763 & -0.72 \\
\hline 24chasa.bg & Bulgaria & 2009 & 11155 & 193 & -0.60562 & -0.87971 \\
\hline The Globe and Mail & Canada & 2007 & 1619504 & 551 & -0.42419 & 4.15662 \\
\hline Journal de Montréal & Canada & 2009 & 193113 & 1348 & -0.58277 & 0.64408 \\
\hline National Post & Canada & 2008 & 747105 & 11865 & -0.17439 & 0.39556 \\
\hline Toronto Star & Canada & 2008 & 829568 & 500 & 0.9212 & -0.27879 \\
\hline La Presse & Canada & 2007 & 659730 & 201 & -0.56099 & -0.4886 \\
\hline 24sata & Croatia & 2009 & 154017 & 1873 & -0.40942 & 0.06158 \\
\hline Vecernji list & Croatia & 2009 & 148642 & 590 & -0.48625 & -0.50024 \\
\hline NOVI LIST & Croatia & 2009 & 82900 & 1292 & -0.53553 & -0.76516 \\
\hline Jutarnji List & Croatia & 2015 & 10865 & 738 & -0.58662 & -0.84759 \\
\hline Hospodárské noviny & Czech Republic & 2009 & 178800 & 315 & -0.11111 & -0.6051 \\
\hline Blesk Zprávy & Czech Republic & 2015 & 1539 & 146 & -0.48167 & -0.64054 \\
\hline Deník.cz & Czech Republic & 2009 & 1408 & 85 & -0.46528 & -0.79059 \\
\hline MF DNES & Czech Republic & 2009 & 29635 & 76 & -0.60612 & -0.94534 \\
\hline Lidové noviny & Czech Republic & 2014 & 3059 & 488 & -0.39438 & -0.97645 \\
\hline BT & Denmark & 2010 & 9307 & 542 & -0.43883 & 0.04689 \\
\hline Jyllands-Posten & Denmark & 2009 & 25793 & 555 & -0.28026 & -0.10158 \\
\hline Politiken & Denmark & 2008 & 195746 & 213 & -0.47224 & -0.66323 \\
\hline Berlingske & Denmark & 2008 & 117674 & 460 & -0.36252 & -0.67321 \\
\hline Børsen & Denmark & 2009 & 12095 & 5 & -0.30428 & -0.92481 \\
\hline Äripäeva uudised & Estonia & 2009 & 3517 & 37 & -0.57159 & -0.56055 \\
\hline Õhtuleht & Estonia & 2009 & 292 & 13 & -0.58412 & -0.66294 \\
\hline Pärnu Postimees & Estonia & 2009 & 1011 & 11 & -0.58963 & -0.72532 \\
\hline Eesti Päevaleht & Estonia & 2010 & 2873 & 64 & -0.59605 & -0.78732 \\
\hline Postimees & Estonia & 2008 & 4380 & 13 & -0.59732 & -0.79964 \\
\hline Turun Sanomat & Finland & 2010 & 13264 & 91 & -0.71914 & -0.24415 \\
\hline Ilta-Sanomat & Finland & 2009 & 226683 & 102 & -0.54991 & -0.46352 \\
\hline Helsingin Sanomat & Finland & 2009 & 241826 & 2287 & -0.41862 & -0.59143 \\
\hline Iltalehti & Finland & 2009 & 72383 & 813 & -0.38095 & -0.81479 \\
\hline Aamulehti & Finland & 2009 & 67449 & 108 & -0.42455 & -0.91601 \\
\hline Ouest-France & France & 2009 & 508402 & 4155 & -0.18574 & 1.5321 \\
\hline Le Monde & France & 2009 & 7354906 & 449 & 2.61495 & 1.27395 \\
\hline Le Figaro & France & 2007 & 2734979 & 519 & 2.05144 & 0.61912 \\
\hline Sud Ouest & France & 2009 & 401438 & 1743 & 0.80064 & -0.35049 \\
\hline L'ÉQUIPE & France & 2009 & 4655567 & 1752 & 1.03448 & -0.44815 \\
\hline
\end{tabular}




\begin{tabular}{|c|c|c|c|c|c|c|}
\hline Media outlet & Nation & Online & Followers & Followings & $\begin{array}{r}\text { Interaction } \\
\text { FAC1 }\end{array}$ & $\begin{array}{r}\text { Exposure } \\
\text { FAC2 }\end{array}$ \\
\hline Süddeutsche Zeitung & Germany & 2010 & 1352741 & 406 & 0.13352 & 0.43129 \\
\hline HAZ & Germany & 2008 & 75811 & 133 & -0.25065 & 0.38424 \\
\hline BILD & Germany & 2007 & 1648609 & 526 & 0.00697 & -0.13322 \\
\hline Augsburger Allgemeine & Germany & 2009 & 21296 & 1045 & -0.3433 & -0.32206 \\
\hline Rheinische Post & Germany & 2008 & 194214 & 1317 & 0.67004 & -0.67157 \\
\hline To Vima & Greece & 2010 & 168252 & 57 & -1.52176 & 3.99211 \\
\hline TA NEA & Greece & 2009 & 129823 & 219 & -0.69256 & 1.77194 \\
\hline Kathimerini & Greece & 2010 & 297850 & 350 & -0.52591 & 0.51471 \\
\hline Nemzeti Sport & Hungary & 2009 & 9147 & 28 & -1.07663 & 1.49047 \\
\hline Blikk Hu & Hungary & 2010 & 3818 & 101 & -0.50663 & 0.05033 \\
\hline kisalfold.hu & Hungary & 2009 & 821 & 44 & -0.65697 & -0.48516 \\
\hline Irish Sun & Ireland & 2012 & 10860 & 291 & -0.31728 & 1.20018 \\
\hline Independent.ie & Ireland & 2009 & 404251 & 254 & -0.07734 & 0.82252 \\
\hline The Irish Times & Ireland & 2008 & 367581 & 139 & 2.17522 & 0.02402 \\
\hline The Irish Daily Mail & Ireland & 2015 & 3570 & 140 & -0.4894 & -0.76394 \\
\hline Irish Daily Star & Ireland & 2012 & 9698 & 224 & -0.04191 & -1.04074 \\
\hline La Gazzetta dello Sport & Italy & 2009 & 1671650 & 271 & 0.09267 & 2.09656 \\
\hline la Repubblica & Italy & 2009 & 2721785 & 264 & -0.06266 & 1.44121 \\
\hline La Stampa & Italy & 2009 & 954577 & 353 & 0.61434 & 0.98585 \\
\hline Corriere della Sera & Italy & 2011 & 1961127 & 290 & 0.55642 & 0.38382 \\
\hline IlSole24ORE & Italy & 2011 & 1250175 & 481 & -0.39823 & -0.24468 \\
\hline Sport Ekspress (rus) & Latvia & 2010 & 253348 & 284 & 0.07528 & 0.57966 \\
\hline nra.lv & Latvia & 2009 & 13084 & 6667 & -0.45227 & 0.07952 \\
\hline Diena & Latvia & 2009 & 68299 & 8671 & -0.50474 & -0.18126 \\
\hline Dienas Bizness & Latvia & 2009 & 17453 & 40 & -0.59463 & -0.59502 \\
\hline LA.lv & Latvia & 2009 & 14242 & 10703 & 0.77609 & -0.86933 \\
\hline Lrytas.lt & Lithuania & 2011 & 4509 & 10 & -0.55512 & -0.39862 \\
\hline Kaunodiena.lt & Lithuania & 2012 & 418 & 15 & -0.58218 & -0.6447 \\
\hline lzinios.lt & Lithuania & 2011 & 485 & 312 & -0.59855 & -0.7953 \\
\hline Tageblatt & Luxembourg & 2010 & 7752 & 610 & -0.54767 & -0.09574 \\
\hline Luxemburger Wort & Luxembourg & 2009 & 14986 & 788 & -0.66219 & -0.18452 \\
\hline Le Quotidien & Luxembourg & 2010 & 3740 & 187 & -0.68313 & -0.38115 \\
\hline Lëtzebuerger Journal & Luxembourg & 2010 & 5039 & 458 & -0.44178 & -0.59485 \\
\hline Luxemburger Wort FR & Luxembourg & 2011 & 11384 & 1106 & -0.61235 & -0.60798 \\
\hline de Volkskrant & Netherlands & 2007 & 697298 & 1520 & 1.48187 & 0.72414 \\
\hline De Telegraaf & Netherlands & 2007 & 537492 & 189 & 0.026 & 0.28775 \\
\hline $\mathrm{NRC}$ & Netherlands & 2007 & 544273 & 263 & 0.04569 & 0.07169 \\
\hline
\end{tabular}




\begin{tabular}{|c|c|c|c|c|c|c|}
\hline Media outlet & Nation & Online & Followers & Followings & $\begin{array}{r}\text { Interaction } \\
\text { FAC1 }\end{array}$ & $\begin{array}{r}\text { Exposure } \\
\text { FAC2 }\end{array}$ \\
\hline AD.nl & Netherlands & 2010 & 316006 & 1015 & 0.78549 & -0.27321 \\
\hline Dagblad Metro & Netherlands & 2009 & 43658 & 67 & 0.66887 & -0.86379 \\
\hline Bergens Tidende & Norway & 2008 & 42676 & 4401 & -0.45165 & -0.49072 \\
\hline DN.no & Norway & 2008 & 54492 & 68 & -0.33954 & -0.82168 \\
\hline Aftenposten & Norway & 2008 & 116833 & 2835 & 0.1527 & -1.10571 \\
\hline Rzeczpospolita & Poland & 2010 & 155398 & 313 & -0.2789 & 2.7306 \\
\hline FAKT24.PL & Poland & 2009 & 22742 & 1688 & -0.20137 & 0.0054 \\
\hline Super Express & Poland & 2009 & 6564 & 795 & -0.32617 & -0.75911 \\
\hline Gazeta Wyborcza.pl & Poland & 2009 & 742845 & 470 & 2.13132 & -0.8308 \\
\hline O Jogo Online & Portugal & 2008 & 134963 & 3405 & -1.58317 & 3.97532 \\
\hline Diário Record & Portugal & 2009 & 295424 & 1130 & -0.02812 & 0.80246 \\
\hline Público & Portugal & 2007 & 646100 & 113 & -0.30929 & 0.50254 \\
\hline Correio da Manhã & Portugal & 2010 & 342296 & 1202 & -0.46414 & 0.48127 \\
\hline Jornal de Notícias & Portugal & 2008 & 444101 & 12905 & -0.48346 & 0.23599 \\
\hline Libertatea Online & Romania & 2009 & 9406 & 153 & -0.47254 & 0.45012 \\
\hline Plus JEDEN DEN & Slovakia & 2013 & 2206 & 38 & -0.56877 & -0.65094 \\
\hline Ûj Szó & Slovakia & 2009 & 843 & 24 & -0.58669 & -0.70165 \\
\hline Vecer & Slovenia & 2007 & 16077 & 1629 & -0.29403 & 0.01851 \\
\hline Slovenske Novice & Slovenia & 2010 & 8243 & 821 & -0.56106 & -0.43713 \\
\hline Casnik Delo & Slovenia & 2010 & 56239 & 515 & 1.29967 & -0.565 \\
\hline Primorske novice & Slovenia & 2014 & 2043 & 310 & -0.4046 & -0.61003 \\
\hline Svet24 & Slovenia & 2012 & 700 & 221 & -0.60802 & -0.89442 \\
\hline La Vanguardia & Spain & 2009 & 827031 & 506 & -0.42948 & 1.59469 \\
\hline MARCA & Spain & 2008 & 4684491 & 1596 & 2.72265 & 1.25485 \\
\hline EL PAÍS & Spain & 2007 & 6258065 & 768 & 1.98881 & 1.03874 \\
\hline EL MUNDO & Spain & 2008 & 2865839 & 1333 & 3.18458 & 0.14689 \\
\hline AS & Spain & 2007 & 2311561 & 1066 & 3.05803 & 0.09435 \\
\hline Dagens industri & Sweden & 2011 & 54677 & 4835 & -0.1674 & -0.4176 \\
\hline Barometern & Sweden & 2010 & 4219 & 35 & -0.58629 & -0.57859 \\
\hline Dagens Nyheter & Sweden & 2012 & 201822 & 40736 & -0.1722 & -0.64005 \\
\hline Aftonbladet & Sweden & 2009 & 105808 & 9557 & -0.24776 & -0.867 \\
\hline Borås Tidning & Sweden & 2010 & 4340 & 316 & -0.57007 & -0.8916 \\
\hline Blick & Switzerland & 2009 & 234837 & 948 & -0.07515 & -0.47994 \\
\hline Tages-Anzeiger & Switzerland & 2010 & 160548 & 1119 & 0.9543 & -0.56258 \\
\hline Südostschweiz & Switzerland & 2009 & 4165 & 630 & -0.44977 & -0.68368 \\
\hline bernerzeitung.ch & Switzerland & 2009 & 10432 & 65 & -0.59672 & -0.70739 \\
\hline Neue Zürcher Zeitung & Switzerland & 2008 & 363624 & 2447 & 1.15677 & -0.71534 \\
\hline Daily Star & United Kingdom & 2009 & 172823 & 3631 & -0.24381 & 2.49463 \\
\hline
\end{tabular}


ROSSELLA REGA

\begin{tabular}{|c|c|c|c|c|c|c|}
\hline Media outlet & Nation & Online & Followers & Followings & $\begin{array}{r}\text { Interaction } \\
\text { FAC1 }\end{array}$ & $\begin{array}{r}\text { Exposure } \\
\text { FAC2 }\end{array}$ \\
\hline The Sun & United Kingdom & 2009 & 1309825 & 386 & 0.58253 & 1.26581 \\
\hline The Telegraph & United Kingdom & 2008 & 2203506 & 603 & -0.53183 & 1.09073 \\
\hline Daily Mirror & United Kingdom & 2008 & 929437 & 6284 & 1.32335 & 0.27442 \\
\hline Daily Mail Online & United Kingdom & 2008 & 2035905 & 2404 & 0.43061 & -0.06776 \\
\hline Wall Street Journal & USA & 2007 & 14506315 & 1074 & -0.11288 & 0.88067 \\
\hline USA TODAY & USA & 2008 & 3399466 & 452 & 3.02717 & 0.6161 \\
\hline Los Angeles Times & USA & 2008 & 2962344 & 10680 & 0.54921 & 0.11854 \\
\hline New York Post & USA & 2008 & 1291320 & 12042 & 0.4422 & -0.11406 \\
\hline The New York Times & USA & 2007 & 38814352 & 887 & 5.41859 & -0.69351 \\
\hline
\end{tabular}

